\title{
Characteristics of Wood Tar Produced as Byproduct from Two Types of The Kiln in The Manufacture of Oak Charcoal ${ }^{1}$
}

\author{
Bong Suk Yang ${ }^{2}$ Jiwook Yang ${ }^{2}$ Dae-Young $\mathrm{Kim}^{2}$ • \\ Jin-Kyu Kim ${ }^{3} \cdot$ Won-Jung Hwang ${ }^{4} \cdot$ Gu-Joong Kwon (iD ${ }^{2, \dagger}$
}

\begin{abstract}
This study investigated the characteristics of wood tar, produced as a byproduct during the production of charcoal using oak wood by the modified traditional kiln and mechanical steel kiln. The wood tar was analyzed with a number of techniques, including Py-GC/MS, NMR, MALDI-TOF, FT-IR, TG and DSC. The Py-GC/MS analysis indicated that modified traditional kiln generated a higher hydrocarbon ratio in the wood tar than that of mechanical steel kiln. On the other hand, mechanical steel kiln resulted in a higher proportion of phenolic and aromatic hydrocarbon components than that of modified traditional kiln. Those results were also confirmed by NMR analysis. The MALDI-TOF analysis suggested that the wood tar produced in the mechanical steel kiln had a slightly higher molecular weight than the wood tar produced in the modified traditional kiln. In addition, the FT-IR analysis showed characteristic peak of symmetrical stretching vibration of $\mathrm{CH}_{3}$ from the modified traditional kiln while characteristic peaks of the $\mathrm{C}-\mathrm{C}$ and $\mathrm{C}-\mathrm{O}$ stretching vibration were observed from the mechanical steel kiln. Moreover, TG and DSC analysis suggested that the mechanical steel kiln is more thermally stable than that of modified traditional kiln. Those findings clearly showed that the method of making charcoal greatly affects the properties of wood tar.
\end{abstract}

Keywords : wood tar, traditional kiln, mechanical steel kiln, lignin, pyrolysis

\section{INTRODUCTION}

Charcoal has long been used for agriculture and fuel in many countries (Rocha et al., 2002; Steiner et al., 2004; Yatagai et al., 1986). Today, the supply of gas, electricity and oil has reduced the production of charcoal, however, developing countries are still producing charcoal for fuel. Recently, in Korea and Japan, the value of charcoal has been re-evaluated again as a subject of interest as nature and health-friendly material. In developing countries, the use of kilns such as Degussa-retort, Lambiotte process and Calusco tunnel retort is widely used in the

1 Date Received September 18, 2017, Date Accepted October 30, 2017

2 College of Life Science \& Biotechnology, Dongguk University, Goyang-Si 10326, Republic of Korea

3 Gyeonggido Business \& Science Accelerator, Suwon-Si 16229, Republic of Korea

4 Department of Forest Products, Korea Forest Research Institute, Seoul 02455, Republic of Korea

† Corresponding author: Gu-Joong Kwon (e-mail: gjkwon@dongguk.edu, ORCID: 0000-0002-4338-5591) 
manufacture of charcoal (Griessacher et al., 2012). In the manufacturing process of charcoal, the constituents of wood are discharged as smoke, pyrolysis product, and liquid woody vinegary like substance is obtained as a by-product by air or water cooling. Crude wood vinegar is divided into three layers when left standing for an extended period. A thin layer of light oil on the uppermost layer, water-soluble light brown wood vinegar in the middle layer, and a black oily liquid wood tar is formed in the low layer.

Liquid vinegars of various compounds such as acetic acid and alcohol, organic acids, and phenols, which are formed by pyrolysis of wood constituents (cellulose, hemicellulose, and lignin) (Mohan et al., 2006; Mun and $\mathrm{Ku}$, 2010). This wood vinegar is widely used as fertilizer. Wood tar is a substance obtained by pyrolysis of lignin (Wenzl, 1970), which is a complex mixture of aromatics and oxygenated compounds mainly composed of aromatic hydrocarbons (Amen-Chen et al., 1997; Blanco et al., 2012).

Lignin is an aromatic polymer that accounts for about 15-36\% (Brebu et al., 2011; Liu et al., 2015; Saiz-Jimenez and De Leeuw, 1986) of woody biomass resources and is an amorphous material that does not have a uniform bonding unit. This ingredient is attracting attention as a renewable raw material due to the increase in market price of aromatic (petroleum) chemicals and the increase in production of shale gas in the United States (De Wild et al., 2014). Currently, Lignin is produced in a large amount in pulp mills, and research is being actively carried out to replace lignin with raw materials such as resin and plastic (Lee and Deng, 2015; Lora and Glasser, 2002; Park et al., 2008; Setua et al., 2000; Zhao et al., 2001). In addition, it is considered to be a source of potential chemical substances and has received much attention in research on pyrolysis lignin (Brebu and Vasile, 2010). Pyrolysis lignin can be used as an auxiliary in the wood-based industry since pyrolysis is an economical thermochemical process capable of converting $60-75 \%$ (by mass) of biomass into energy-dense crude oil (Jiang et al., 2010; Scholze et al., 2001). In addition, lignin can be produced as an inexpensive industrial raw material, and carbon fiber manufacturing research is being conducted as a precursor for producing low-cost carbon fiber (Jung et al., 2016). This is because carbon materials are attracting attention as an alternative to energy conservation, and the spread of carbon materials in the materials and components industries worldwide is expected to increase. Studies around the world show that coal and petroleum tar are the most promising candidates for advanced carbon material precursors. However, considering the economic and technological aspects such as lignin, it is possible to obtain many materials that can be applied from abundant and inexpensive raw materials, and to pay attention to resources that are based on the biomass of fossil resources (Prauchner et al., 2001). Therefore, it is expected that lignin-derived wood tar will be used in the future. Since these wood tar vary in the 
process, maturity temperature, and other factors, it is necessary to study the wood tar according to each manufacturing process (Sarohia et al., 2014).

The production of charcoal in Korea has been conducted modified traditional kiln and mechanical steel kiln. Modified traditional kiln is constructed of clay and refractory bricks. It has been modified to improve the convenience and yield of charcoal. It is widely used for the production of black and white charcoal. Black charcoal refers to charcoal produced by carbonizing wood at 350 to $400{ }^{\circ} \mathrm{C}$ raising the temperature to about $700^{\circ} \mathrm{C}$ at the end, refining the charcoal, and cooling it sufficiently to cool the wood. White charcoal is produced by carbonizing wood at a relatively low temperature for several hours at the end of the process, raising the kiln temperature to about $1000^{\circ} \mathrm{C}$ at the end of the process, removing the charcoal and covering it with powder and cooling it quickly. The mechanical steel kiln produces charcoal in the temperature condition of $400-500^{\circ} \mathrm{C}$ by using a closed machine device. In Korea, about $90 \%$ of the kilns used for the production of charcoal modified traditional kiln. Such wood tar is a combustible liquid, which has no apparent industrial use. Then, it is burned or abandoned, which causes environmental pollutants. Therefore various have been conducted to solve the problem (Ahn and Lee, 2014; Ku and Mun, 2006; Kwon et al., 2011; Kwon et al., 2010; Mun et al., 2007).

At present, massive wastes from industrial development are polluting the global environ- ment, and this threatens the life of mankind in the future. As the environmental and sustainability problems increase, waste disposal becomes increasingly important, and new recycling methods are being sought. Therefore, it is necessary to examine the properties of wood tar for utilization of effective resources of wood tar that remain as waste resources.

This study was conducted to compare the composition, chemical structure and thermal properties of wood tar as a byproduct in the process of making charcoal using modified traditional and mechanical steel kilns.

\section{MATERIALS and METHODS}

\subsection{Materials}

Wood tar from the modified traditional kiln was obtained from the A Company producing charcoal by oak located in Hongcheon-Gun, Gangwon Province. The structure of the improved traditional carbonized furnace was clogged with mud. Since the ceiling is where maximum heat is received from the kiln, it is a structure with a thick steel plate on it, covered with soil, and the steel plate is supported with a thick beam. The chimneys are piled up with stones and clay, making the lower part wider and narrower as it goes up, minimizing the outer air flow back into the kiln. The inside of the kiln is about $340 \mathrm{~cm}$ in width, $310 \mathrm{~cm}$ in length, and $210 \mathrm{~cm}$ in height. The vinegar production start when the smoke has reached 80 $90^{\circ} \mathrm{C}$, and when the temperature reach $150^{\circ} \mathrm{C}$, 
the vinegar production has stopped. The temperature inside the kiln while obtaining vinegar solution is around $600{ }^{\circ} \mathrm{C}$ and it takes about 40 hours to collect wood vinegar during the whole charcoal production period.

The mechanical steel kiln was used in the production of charcoal using oak chips at B Company in Kimhae city, Kyungnam Province. In the case of mechanical steel kiln, the wood chips are less than $10 \mathrm{~mm}$ in size and put into the carbonizer via a conveyor belt. The temperature of the kiln is carbonized at about 400 to $450^{\circ} \mathrm{C}$ with a carbonization time of 5 to 10 minutes. At this time, the gas generated by pyrolysis of the wood is liquefied through the cooling device to produce wood vinegar, and the carbonized charcoal is collected downward. At this time, the amount of carbonized wood is made into a structure in which the wood chip is continuously fed through the conveyor belt.

\subsection{Analysis of Wood tar Composition}

\subsubsection{Pyrolysis-GC/MS measurement}

Component analysis for wood tar was performed using Py-GC/MS. The analytical method was analyzed by dividing the sample into heat detachment section and pyrolytic section and analyzing it at $75-800^{\circ} \mathrm{C}$ by a double shot method which obtains a chromatogram each. Py-GC/MS measurements were carried out using a Double-shot pyrolyzer (PY-2020iD, Frontier Lab. Co. Ltd.) with a $6890 \mathrm{~N}$ GC/MS system (Agilent Tech. Ltd.). A stainless steel capillary column $(30 \mathrm{~m}, 0.25 \mathrm{~mm}$ I.D.) coated with a $0.25 \mu \mathrm{m}$ bonded film of DB-5 ms was used for the separation. The sample $(0.5 \mathrm{mg})$ was placed in a stainless steel sample cup. The cup was placed on top of the pyrolyzer at near ambient temperature. Table 1 shows analysis condition.

\subsection{2. $\mathrm{FT}-\mathrm{IR}$ analysis}

The chemical behavior of the wood tar was evaluated using FT-IR (Fourier Transform Infrared Spectroscopy, Excaliber FT/IR-3000). The $\mathrm{KBr}$ method was used to measure the range of 800 to $4000 \mathrm{~cm}^{-1}$.

\subsubsection{NMR (Nuclear Magnetic Resonance) analysis}

${ }^{1} \mathrm{H}$ and ${ }^{13} \mathrm{C}$ NMR analyses were carried out using Bruker Avance III $700 \mathrm{MHz}$ to examine the chemical structure of the wood. Analytical solvents were determined using $\mathrm{CDCl}_{3}$.

\subsubsection{Molecular weight distribution}

MALDI-TOF (Matrix-Assisted Laser Desorption Ionization-Time of Flight Mass Spectrometry) analysis was performed to examine the molecular weight distribution of wood tar. $\alpha$-Cyano4hydroxycinnamic Acid was used as a matrix for ionization. Samples and matrix were mixed at a ratio of $1: 20$ and coated on a MALDI-TOF plate using a dried droplet method. The plate was dried at room temperature for 12 hours and analyzed. Molecular weights of $60-3000 \mathrm{~m} / \mathrm{z}$ were measured. The equipment used was a Bruker Daltonics Autoflex MALDI-TOF mass spectrometer. 
Table 1. Py-GC/MS conditions for samples analysis

\begin{tabular}{|c|c|}
\hline \multicolumn{2}{|r|}{ Pyrolyzer } \\
\hline Pyrolyzer & Frontier Lab Double-Shot Pyrolyzer PY 2020iD \\
\hline $\begin{array}{l}\text { Pyrolysis temp. } \\
\text { single shot }\end{array}$ & $500^{\circ} \mathrm{C}$ \\
\hline \multicolumn{2}{|r|}{ Gas chromatograph } \\
\hline \multicolumn{2}{|c|}{ Agilent Technologies (Agilent Tech, USA) $6890 \mathrm{~N}$ GC system } \\
\hline Column & Agilent J\&W GC column DB-5 $\mathrm{ms}(30 \mathrm{~m} \times 0.25 \mathrm{~mm} \times 0.25 \mu \mathrm{m})$ \\
\hline Inlet temp & $300^{\circ} \mathrm{C}$ \\
\hline Split & $100: 1$ \\
\hline Gas flow & $1 \mathrm{~m} \ell / \mathrm{min}$ \\
\hline Oven temp. & $40^{\circ} \mathrm{C}(2 \mathrm{~min})---20^{\circ} \mathrm{C} / \mathrm{min}--320^{\circ} \mathrm{C}(14 \mathrm{~min})$ \\
\hline Transfer line temp. & $300^{\circ} \mathrm{C}$ \\
\hline Sample & $0.5 \mathrm{mg}$ \\
\hline \multicolumn{2}{|r|}{ Mass spectrometer } \\
\hline \multicolumn{2}{|c|}{ LECO Pegasus IV (LECO, MI, USA) Time of flight mass spectrometry } \\
\hline Ionization & Electron impact (EI) \\
\hline Solvent delay & $5 \mathrm{sec}$ \\
\hline Mass range & $30-601$ \\
\hline Detector voltage & $1750 \mathrm{~V}$ \\
\hline Ion source temp. & $220^{\circ} \mathrm{C}$ \\
\hline
\end{tabular}

\subsubsection{Thermal properties}

The thermal properties of wood tar were analyzed by TGA (Thermogravimetric analysis) and DSC (Differential Scanning Calorimetry). The thermogravimetric analysis was carried out by thermogravimetry of a $7 \mathrm{mg}$ sample in a nitrogen atmosphere using a thermogravimetric analyzer (Sinco, TGA N-1000) at $600^{\circ} \mathrm{C}$ at a heating rate of $10^{\circ} \mathrm{C} / \mathrm{min}$. Differential scanning calorimetry was performed using a differential scanning calorimeter (Sinco, DSC N-650). The peak of the endothermic or exothermic reactions was observed during the heating of the $2 \mathrm{mg}$ sample to $260^{\circ} \mathrm{C}$ at a rate of $5^{\circ} \mathrm{C} / \mathrm{min}$. In a ni- trogen atmosphere was analyzed.

\section{RESULTS and DISCUSSION}

\subsection{Eletmental Analysis of Wood tar by $\mathrm{Py}-\mathrm{GC} / \mathrm{MS}$}

The chromatogram of the wood tar produced from the modified traditional carbonized furnace using $\mathrm{Py}-\mathrm{GC} / \mathrm{MS}$ at $70-200^{\circ} \mathrm{C}, 300^{\circ} \mathrm{C}$, and $450-800^{\circ} \mathrm{C}$ is given in Fig. 1. Whereas, Fig. 2 is a summary of the peaks in the GC/MS chromatogram by library searching and mass spectrum of acid, alcohol, aldehyde, ketone, furan, phenol, ester and hydrocarbons. Hydrocarbons were most 

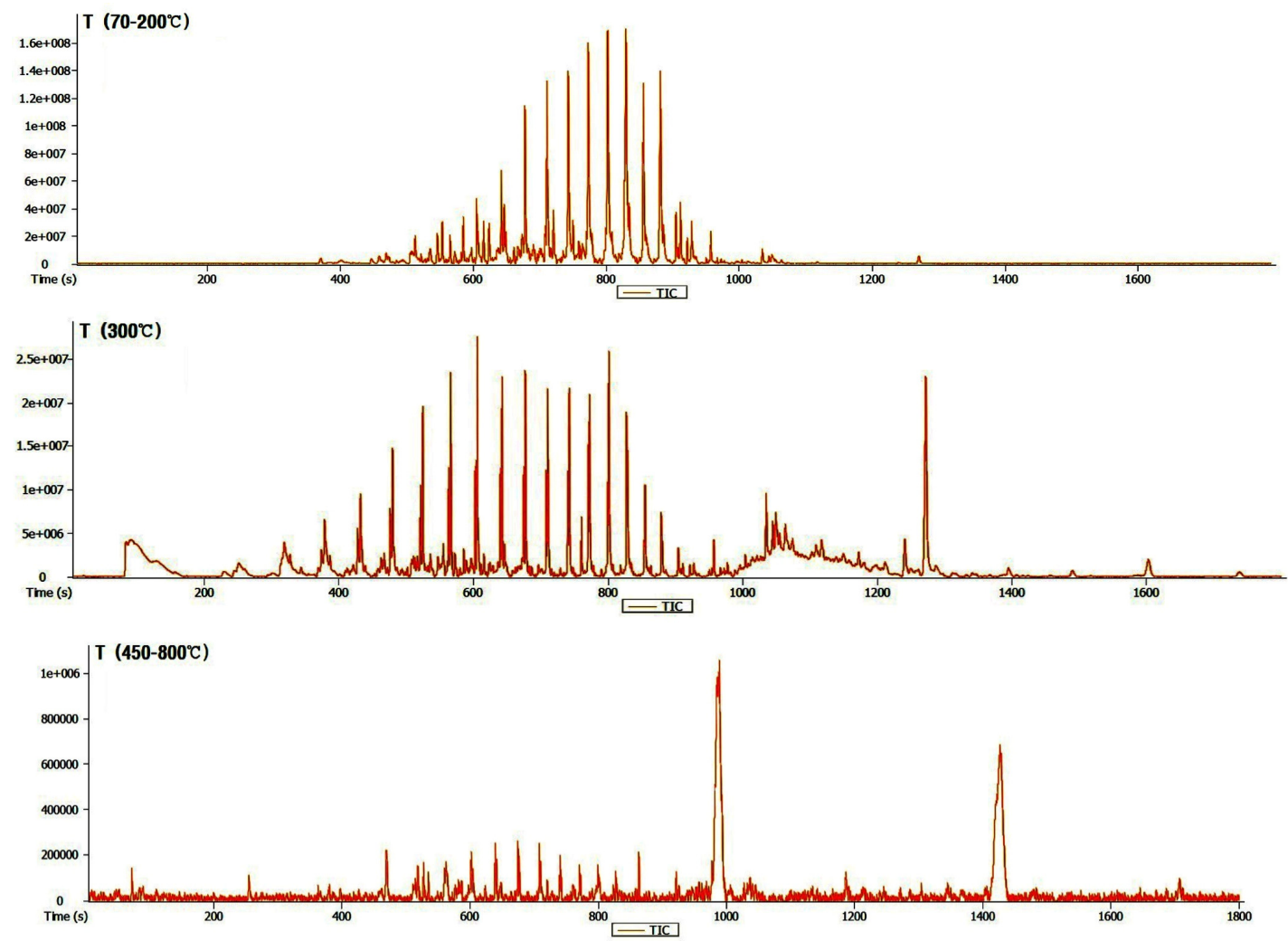

Fig. 1. TIC profile for volatile products separated at different pyrolysis temperatures using wood tar from modified traditional kiln.

abundant in the low-temperature region below $300^{\circ} \mathrm{C}$ and fatty acid ratio in the high temperature region above $450^{\circ} \mathrm{C}$. The acid was detected at a high rate in the condition of $450-850^{\circ} \mathrm{C}$. Overall, the proportion of phenolic compounds was low. The major components detected in each condition are as follows - components such as tetradecane (5.6\%), nonadecane (7.2\%), 2-propyn-1-ol (7.5\%), eicosane $(8.1 \%)$, hexadecane $(10.9 \%)$ and heptacosane $(7.9 \%)$ occupy a large proportion at $70-200{ }^{\circ} \mathrm{C}$. Friedelan-3-one (12.5\%), heneicosane $(5.7 \%)$ and tetradecane $(4.6 \%)$ are the most important components at $300^{\circ} \mathrm{C}$. Hexadecanoic acid

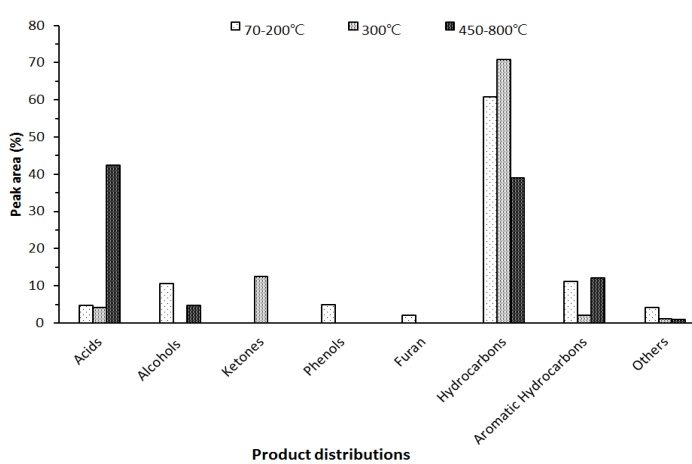

Fig. 2. Comparison of the product distributions from the wood tars of modified traditional kiln.

(17.9\%), methacrylic acid (23.1\%) and 1-docosene (24.2\%) were the most abundant in the high tem- 

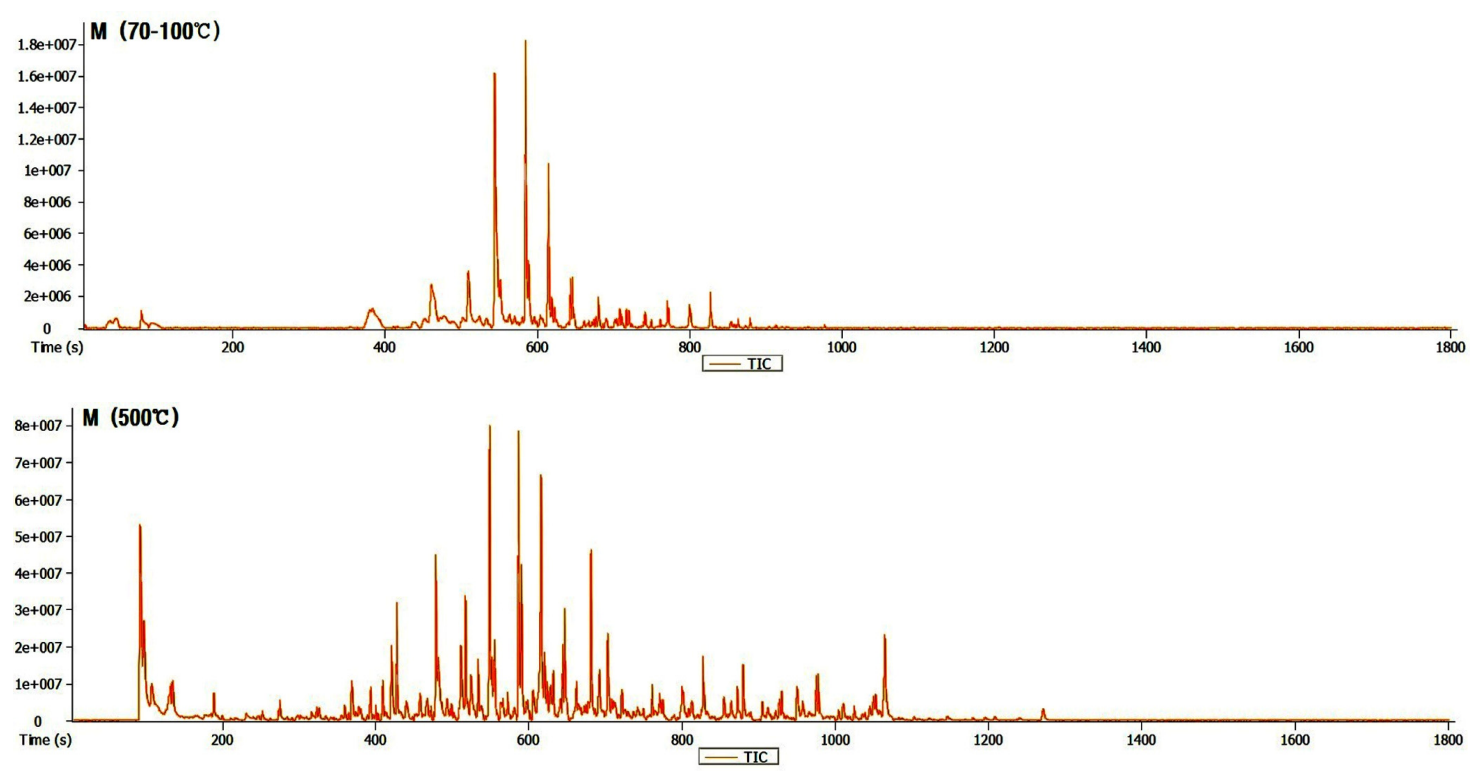

Fig. 3. TIC profile for volatile products separated at different pyrolysis temperatures using wood tar from mechanical steel kiln.

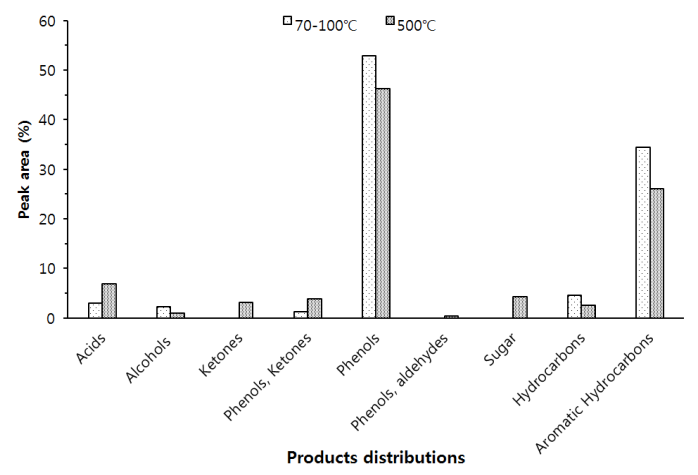

Fig. 4. Comparison of the product distributions from the wood tars of mechanical steel kiln.

perature region $\left(450-800^{\circ} \mathrm{C}\right)$.

The Py-GC/MS chromatogram of the wood tar produced from the mechanical steel kiln Fig. 3, and Fig. 4 show the results of the components identified by library searching and mass spectrum of the detected peaks. Most of the wood tar produced from the mechanical steel kiln was found to contain large amounts of phenolic and aromatic hydrocarbon components. Sugar components were also detected under $500^{\circ} \mathrm{C}$ condition. This could probably be due to pyrolysis of the cellulose and hemicellulose constituents of the wood. At $70-100^{\circ} \mathrm{C}$, components such as cresol (6.6\%), 4-ethyl-2-methoxy-phenol (6.2\%), 2,6-dimethoxy-phenol (25.3\%), 1,2,4-trimethoxy benzene (14.8\%) and 1,2,3-trimethoxy-5-methyl (8.1) were detected. At $500^{\circ} \mathrm{C}$, methyl alcohol (5.5\%), 2,6-dimethoxy-phenol (7.6\%), 1,2,4-trimethoxy benzene (7.5\%), 1,2,3-trimethoxy- benzene $(9.3 \%)$ were detected. Overall, the ratio of phenolic compounds and aromatic compounds were found to be higher in the mechanical steel kiln than in the wood tar produced in the modified traditional kiln.

Ben and Regauskas (2011) reported that the 


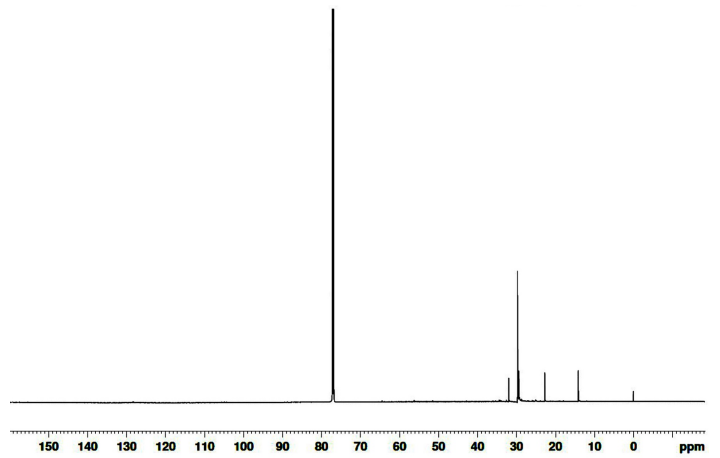

Fig. 5. ${ }^{13} \mathrm{C}$ NMR spectra of the modified traditional kiln wood tar.

formation of pyrolysis oil from lignin is related to pyrolysis temperature (Ben and Ragauskas, 2011), and Iatridis and Gavalas (1979) reported that hydrocarbon production increases with increasing lignin pyrolysis temperature (Iatridis and Gavalas, 1979). In addition, Alen et al. (1996) showed that lignin was converted to primary pyrolysis products such as vanillins and guaiacols at $400{ }^{\circ} \mathrm{C}$, vanillin derivatives were converted to various catechols and phenols at $600^{\circ} \mathrm{C}$, and at above $800^{\circ} \mathrm{C}$, thermoplastic hydrocarbons (Aromatic hydrocarbons) and other phenols were formed as major pyrolysis products (Alén et al., 1996). Therefore, it is considered that the difference in the composition of the wood tar produced in the two kilns is influenced by the carbonization temperature during the production of the charcoal. Since the carbonization temperature of the mechanical steel kiln is set at a condition of $400^{\circ} \mathrm{C}$ to $450{ }^{\circ} \mathrm{C}$, the temperature in the kiln can be controlled. However, since the carbonization temperature of the modified traditional kiln is manual, the temperature control is difficult and the condition in

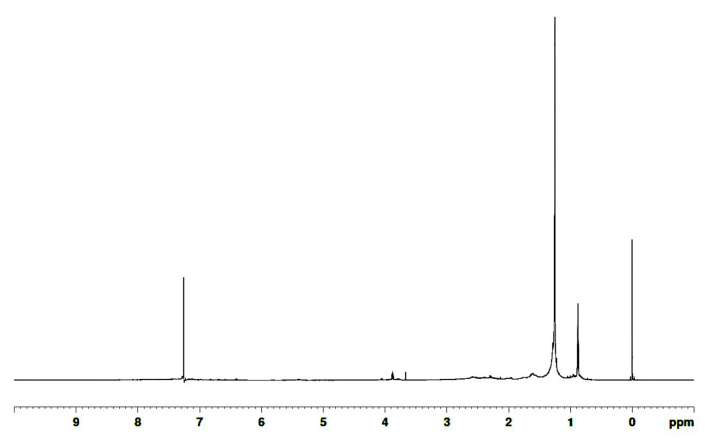

Fig. 6. ${ }^{1} \mathrm{H}$ NMR spectra of the modified traditional kiln wood tar.

which the wood tar is produced is generated at a high temperature $\left(600^{\circ} \mathrm{C}\right)$ compared to the mechanical steel kiln. Due to this reason, it is considered that there is a difference in the composition of the wood tar produced from the modified traditional kiln and the wood tar produced from the mechanical steel kiln.

\subsection{Structural Analysis of wood tar by NMR}

${ }^{13} \mathrm{C}$ NMR and ${ }^{1} \mathrm{H}$ NMR were used to evaluate the properties of the functional groups of the wood tars produced from the modified traditional kiln and the mechanical steel kiln. The results of ${ }^{13} \mathrm{C}$ NMR analysis of the wood tar produced in the modified traditional kiln in chloroform is shown in Fig. 5. The internal reference material peak at $0.0004 \mathrm{ppm}$, followed by 14 ppm aliphatic carbon equivalent signal, a $23 \mathrm{ppm}$, and $32 \mathrm{ppm}$ aliphatic signal, and a 77 ppm chloroform solvent peak. The ${ }^{1} \mathrm{H}$ NMR spectra of the wood tar produced from the modified traditional kiln are given Fig. 6, with the internal standard material signal at $0.0 \mathrm{ppm}$, 


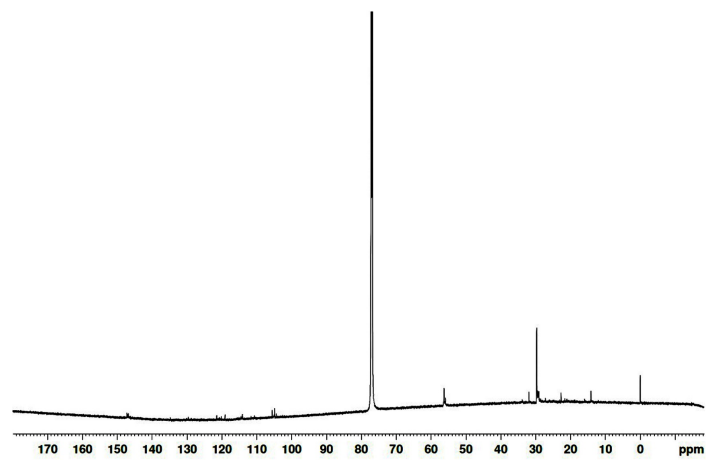

Fig. 7. ${ }^{13} \mathrm{C}$ NMR spectra of the mechanical steel kiln wood tar.

and $7.3 \mathrm{ppm}$ solvent signal. A signal corresponding to the aliphatic proton is between 0.9 to $1.3 \mathrm{ppm}$, this region represents a $\mathrm{C}=\mathrm{C}$ double bond or an aliphatic proton attached to a carbon atom with at least two bonds removed from a heteroatom $(\mathrm{O}$ or $\mathrm{N})$ [29]. A 3.6 - 3.8 ppm signal of the $\mathrm{CH}_{2}$ bridge (diphenylmethane), represents a methylene group linking a proton or two aromatic rings in the aliphatic alcohol or the carbon atom next to the ether (Mullen et al., 2009).

The results of ${ }^{13} \mathrm{C}$ NMR analysis of the wood tar produced in the mechanical steel kiln are given in Fig. 7. A signal corresponding to aliphatic is seen at $30 \mathrm{ppm}$, and $56 \mathrm{ppm}$ shows methoxyl group signal of aromatic compound. Signals for aromatic compounds appeared in the 105 to 148 ppm range. Fig. 8 shows the results of ${ }^{1} \mathrm{H}$ NMR analysis for the wood tar produced in the mechanical steel kiln. In the wood tar of mechanical steel kiln, a signal corresponding to aliphatic proton appeared at $1.3 \mathrm{ppm}$ and a signal corresponding to $\mathrm{CH}_{2}$ bridge (diphenylmethane) appeared at around $3.8 \mathrm{ppm}$. A comparison of

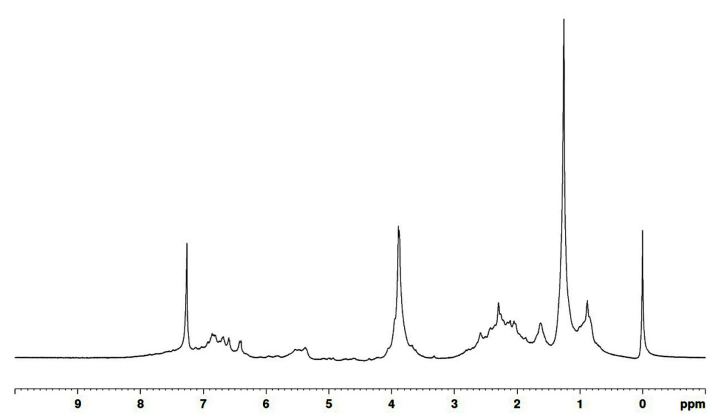

Fig. 8. ${ }^{1} \mathrm{H}$ NMR spectra of the mechanical steel kiln wood tar.

the ${ }^{13} \mathrm{C}$ NMR spectra of the modified traditional kiln wood tar and mechanical steel kiln wood tar shows that the aromatic compound signal was observed in the wood tar of the mechanical steel kiln. However, when comparing the ${ }^{1} \mathrm{H}$ NMR spectra, the overall pattern was similar.

\subsection{Molecular Weight Distribution of Wood tar by MALDI-TOF}

Fig. 9 shows the MALDI-TOF spectra of the matrix and standard calibration used to measure the molecular weight distribution of wood tar. The $\mathrm{x}$ axis represents the molecular weight of the cation by mass / charge and the y axis represents the absolute intensity. Molecular weight distribution of wood tar was analyzed except for the peaks in the matrix and standard calibration. Fig. 10 shows the molecular weight distribution of wood tar on samples using MALDI-TOF mass spectrometry. The modified traditional kiln wood tar (Fig. 10a) has a molecular weight ranging from 260 to $680 \mathrm{~m} / \mathrm{z}$. The mechanical steel kiln wood tar (Fig. 10b) 

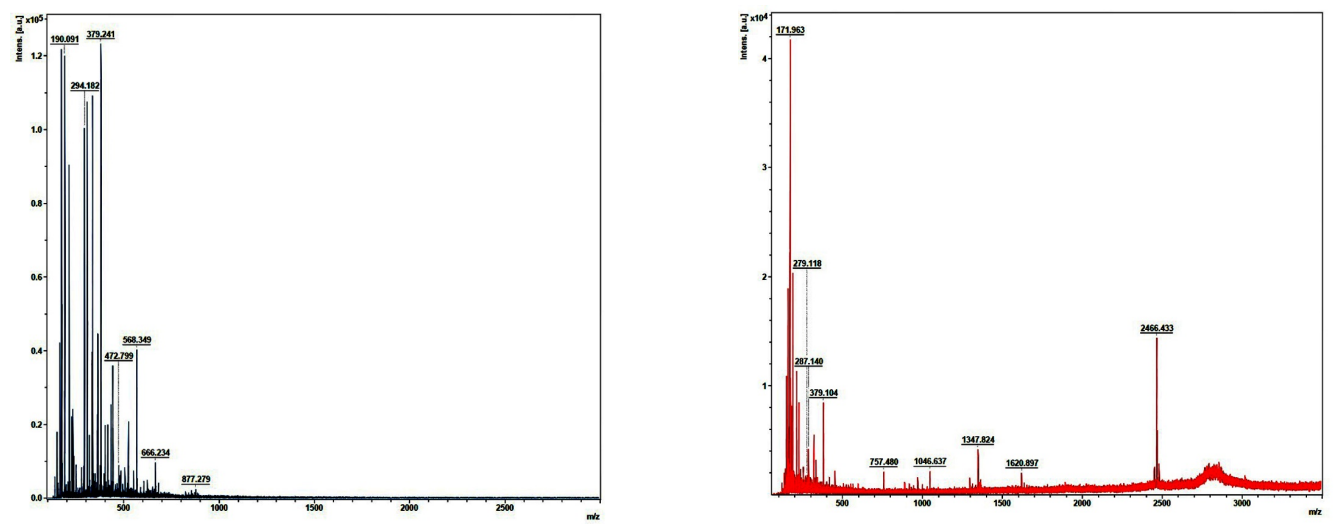

Fig. 9. MALDI-TOF spectra of matrix (left) and Standard calibration (right).

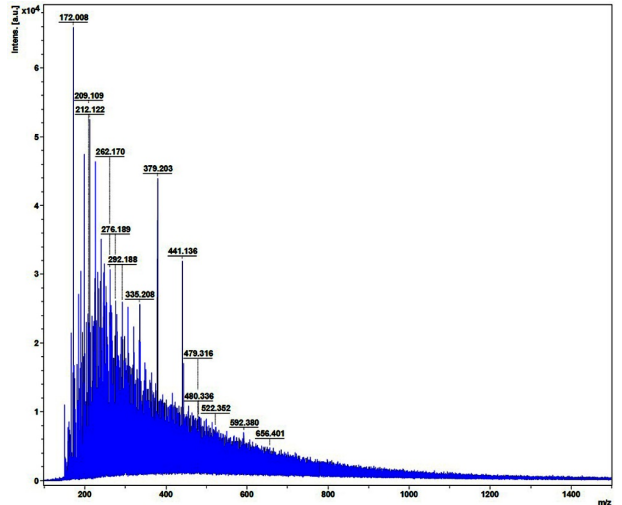

(A)

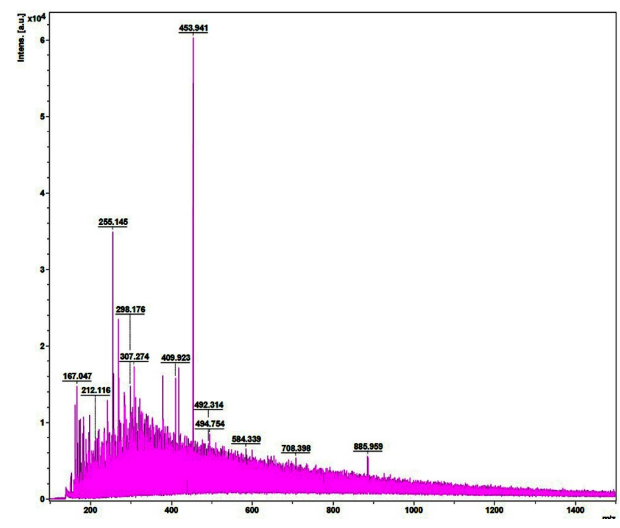

(B)

Fig. 10. Molecular weight distribution of modified traditional kiln wood tar (A) and mechanical steel kiln wood $\operatorname{tar}(\mathrm{B})$.

shows a molecular weight distribution in the range of 255 to $880 \mathrm{~m} / \mathrm{z}$, indicating that there is a somewhat broader range of molecular weight than the wood tar produced in the modified traditional kiln.

The molecular weight distribution of the wood tar analyzed by MALDI-TOF is shown in Fig. 11. Molecular weight classification of wood tar was divided into fraction 1 (1-149 $\mathrm{m} / \mathrm{z})$, fraction $2(150-299 \mathrm{~m} / \mathrm{z})$, fraction 3

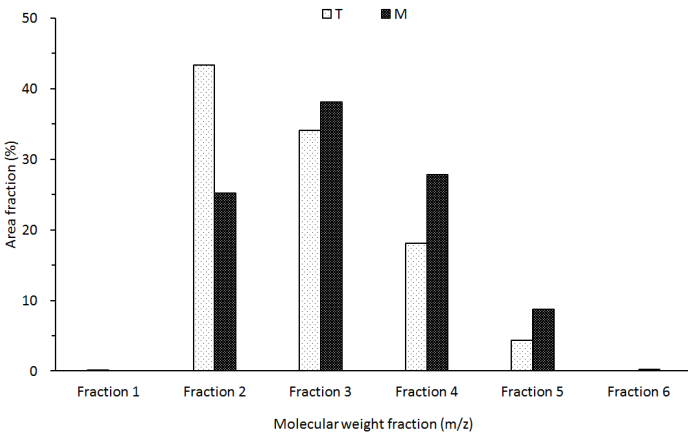

Fig.11. Diagram of the molecular weight fraction divided by the pseudo component. (300-449 $\mathrm{m} / \mathrm{z})$, fraction $4(450-599 \mathrm{~m} / \mathrm{z})$, frac- 

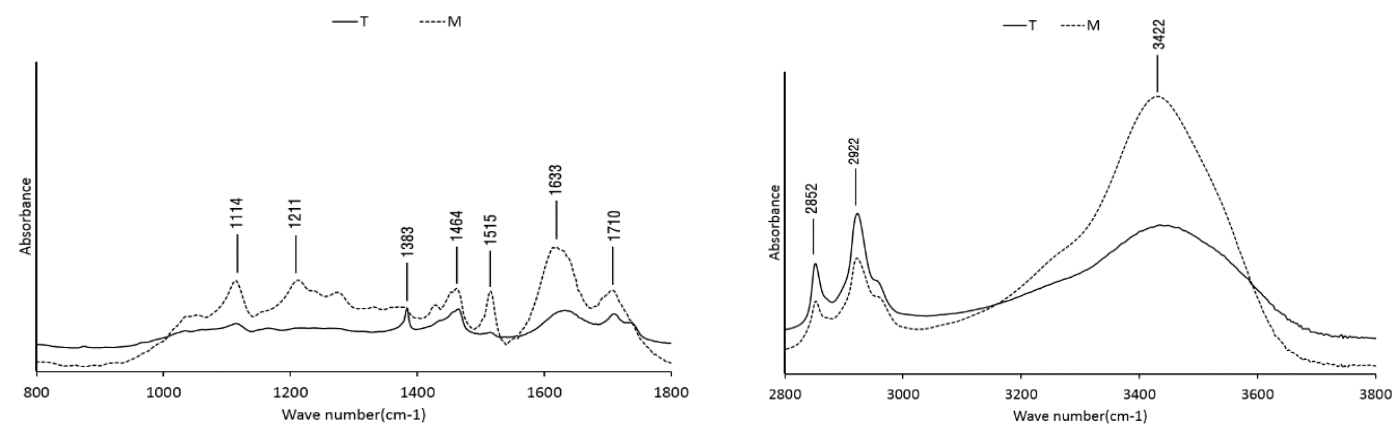

Fig. 12. FT-IR spectra of wood tars of modified traditional kiln (T) and mechanical steel kiln (M).

tion $5(600-749 \mathrm{~m} / \mathrm{z})$, and fraction $6(750-899$ $\mathrm{m} / \mathrm{z}$ ). The average molecular weight distribution of the wood tar (Fig. 11. T) produced in the modified traditional kiln shows the highest distribution in Fraction 2, suggesting that many compounds with molecular weights of 150-299 $\mathrm{m} / \mathrm{z}$ exist. The fraction of wood (Fig. 11. M) produced in the mechanical steel kiln was the highest in fraction 3. A comparison of the average molecular weight distributions of the two wood tars indicates that the tar-oligomers present in the mechanical steel kiln are present in a higher degree of polymerization than the wood tar produced in the modified traditional kiln.

\subsection{Wood tar Analysis by FT-IR}

The FT-IR spectra of the wood tars produced from the modified traditional kiln and the mechanical steel kilns are shown in Fig. 12. In both wood tars, $1114 \mathrm{~cm}^{-1}$ (C-O-C stretch of aliphatic ether), $1464 \mathrm{~cm}^{-1}$ (CH bending deformations and aromatic ring vibrations), 1633 $\mathrm{cm}^{-1}$ (stretching of aromatic $\mathrm{C}=\mathrm{C}$ groups), 1710 $\mathrm{cm}^{-1}\left(\mathrm{CH}_{3}\right.$ and $\mathrm{CH}_{2}$ groups) and $3434 \mathrm{~cm}^{-1}(\mathrm{OH}$ group of phenolic and aliphatic structure) peaks are seen. However, the symmetrical stretching vibration of $\mathrm{CH}_{3}$ was observed at $1383 \mathrm{~cm}^{-1}$ in the wood tar produced from the modified traditional kiln. C-C and C-O stretching vibration peaks were observed at $1211 \mathrm{~cm}^{-1}$ in the wood tar produced from the mechanical steel kiln. Ben \& Ragauskas (2011) suggested that formation of aromatic $\mathrm{C}-\mathrm{O}$ bonds are due to radical reactions between aromatic and aliphatic hydroxyl groups, and aromatic $\mathrm{C}-\mathrm{C}$ bonds are formed by cleavage of methoxyl groups and aromatic C-H bonds during pyrolysis (Ben and Ragauskas, 2011). FT-IR analysis showed that the structure of the wood tar produced by the pyrolysis of the aliphatic side of the lignin component affected the characteristics of the wood tar structure.

\subsection{Thermal Properties of Wood tar using TG and DSC}

The results of thermogravimetric analysis of the modified traditional kiln and the mechanical steel kiln are shown in Fig. 13. As seen in Fig. 


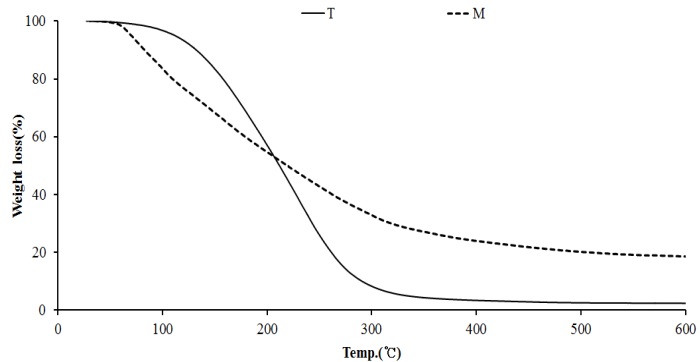

Fig. 13. Weight loss curve of wood tars for improved traditional kiln (T) and mechanical steel kiln (M).

13 (T), pyrolysis started at $143^{\circ} \mathrm{C}$ and proceeded to $287^{\circ} \mathrm{C}$. At this temperature range, the weight decreased to about $94 \%$. Thereafter, pyrolysis proceeded gradually. The final yield at $600^{\circ} \mathrm{C}$ was about $3 \%$. The wood tar (Fig. 13, $\mathrm{M})$ produced from the mechanical steel kiln began pyrolysis at $50^{\circ} \mathrm{C}$ and proceeded rapidly to $300^{\circ} \mathrm{C}$, with a $72 \%$ decrease in weight. Thereafter, the weight was gradually decreased, and the final yield was $17 \%$ at $600^{\circ} \mathrm{C}$. The pyrolysis initiation temperature of the two samples was low in the manganese produced from the mechanical steel kiln. However, the final yield was high for the wood tar produced by the mechanical steel kiln.

Fig. 14 DTG curve for wood tar produced from the modified traditional kiln showed a weight reduction rate in the temperature range of $80^{\circ} \mathrm{C}$ to $350^{\circ} \mathrm{C}$. The temperature range of $220-240^{\circ} \mathrm{C}$ showed the highest weight loss rate. However, the wood tar produced from the mechanical steel kiln showed a weight reduction rate in the temperature range of $50-340{ }^{\circ} \mathrm{C}$. Among them, the highest weight reduction rate was seen in the temperature range of $70-110^{\circ} \mathrm{C}$.

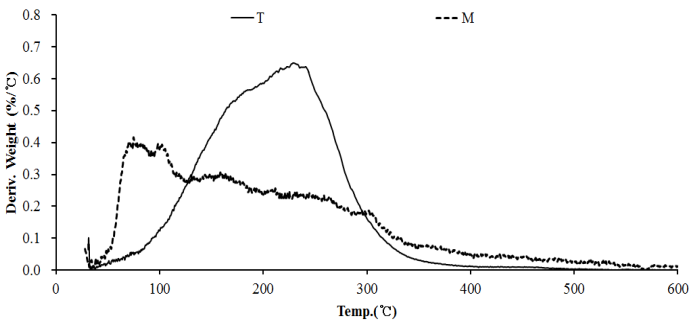

Fig. 14. DTG of wood tars for modified traditional kiln (T) and mechanical steel kiln (M).

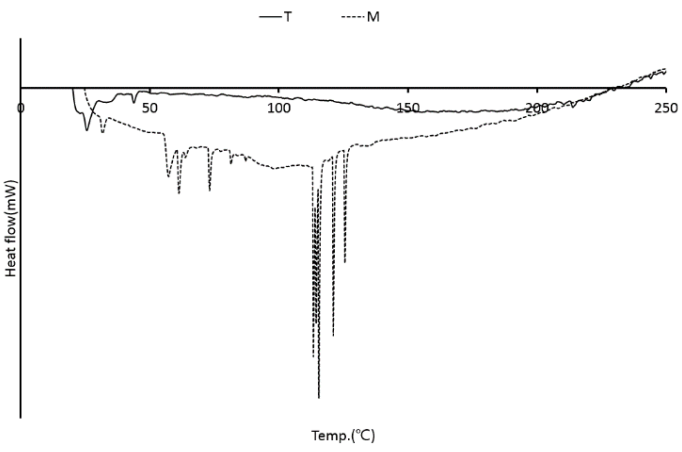

Fig. 15. DSC curves of wood tars for modified traditional kiln (T) and mechanical steel kiln (M).

These results show that volatiles in the initial stage of the mechanical steel kiln is more volatile than those in the modified traditional kiln.

The DSC curve for wood tars produced from the modified traditional kiln and mechanical steel kiln is shown in Fig. 15. The endothermic peaks appear to be melting at temperatures below $60^{\circ} \mathrm{C}$. There were no significant changes. However, the endothermic peaks generated by the melting of various components between $30{ }^{\circ} \mathrm{C}$ and $81{ }^{\circ} \mathrm{C}$ and between $113^{\circ} \mathrm{C}$ and $125^{\circ} \mathrm{C}$ were found in the wood tar produced from the mechanical steel kiln. Mechanical steel kiln wood tar showed higher thermal properties than modified traditional kiln wood tar. Wood tar is 
a substance produced by condensation or polymerization by thermochemical reaction of wood components. It is difficult to control the temperature of the modified traditional kiln when compared with the mechanical carbonization furnace and the pyrolysis compounds generated during the production of charcoal are generated by the thermochemical reaction generated by the long residence time in the carbonization furnace under the high temperature condition. Therefore, it is considered that the temperature during the production of wood vinegar greatly affects the composition of wood tar.

\section{CONCLUSIONS}

The chemical structure and thermal properties of wood tar produced as by - products in the modified traditional kiln and mechanical steel kiln were investigated. Pyrolytic GC/MS and NMR analysis showed that most of the hydrocarbons produced in the modified traditional kiln were the most abundant hydrocarbons, and the wood tar produced in the mechanical steel kiln contained many phenolic and aromatic hydrocarbons. Using MALDI-TOF, the molecular weight of the two kind of wood tars ranged from 255 to $880 \mathrm{~m} / \mathrm{z}$. It has been confirmed that the wood tar produced from the mechanical steel kiln have a higher degree of polymerization than those produced from the modified traditional kiln. The characteristic peak of the symmetrical stretching vibration of $\mathrm{CH}_{3}$ was found in the modified traditional kiln wood tar, and the C-C and C-O stretching vi- bration peaks of the mechanical steel kiln wood tar were characteristic. Due to this structural difference, the wood tar produced in the mechanical steel kiln showed a somewhat higher thermal stability. It was found that the properties of the wood tar significantly affected kiln temperature during wood vinegar recovery and the kiln type.

\section{ACKNOWLEDGEMENT}

This work was supported by the National Research Foundation of Korea (NRF) grant funded by the Korea government (MSIT) (NRF-2016R1A2B4014750).

\section{REFERENCES}

Ahn, B.J., Lee, S.M. 2014. Evaluating The Fuel Characteristics of Wood Pellets Fabricated with Wood Tar and Starch as An Additive. Journal of the Korean Wood Science \& Technology 42(3): 318 326.

Alén, R., Kuoppala, E., Oesch, P. 1996. Formation of the main degradation compound groups from wood and its components during pyrolysis. Journal of Analytical and Applied Pyrolysis 36(2): $137 \sim 148$.

Amen-Chen, C., Pakdel, H., Roy, C. 1997. Separation of phenols from Eucalyptus wood tar. Biomass and Bioenergy 13(1-2): 25 37.

Ben, H., Ragauskas, A.J. 2011. NMR characterization of pyrolysis oils from kraft lignin. Energy \& Fuels 25(5): 2322 2332.

Blanco, P.H., Wu, C., Onwudili, J.A., Williams, P.T. 2012. Characterization of Tar from the Pyrolysis/Gasification of Refuse Derived Fuel: Influence of Process Parameters and Catalysis. Energy \& Fuels 26(4): 2107 2115. 
Brebu, M., Cazacu, G., Chirila, O. 2011. Pyrolysis of lignin - A potential method for obtaining cheminals and/or fuels. Cellulose Chemistry and Technology 45(1-2): 43 50.

Brebu, M., Vasile, C. 2010. Thermal degradation of lignin - A review. Cellulose Chemistry and Technology 44(9): 353 363.

De Wild, P.J., Huijgen, W.J.J., Gosselink, R.J.A. 2014. Lignin pyrolysis for profitable lignocellulosic biorefineries. Biofuels, Bioproducts and Biorefining 8(5): $645 \sim 657$.

Griessacher, T., Antrekowitsch, J., Steinlechner, S. 2012. Charcoal from agricultural residues as alternative reducing agent in metal recycling. Biomass and Bioenergy 39: 139 146.

Iatridis, B., Gavalas, G.R. 1979. Pyrolysis of a Precipitated Kraft Lignin. Industrial \& Engineering Chemistry Product Research and Development 18(2): 127 130 .

Jiang, X., Ellis, N., Zhong, Z. 2010. Characterization of Pyrolytic Lignin Extracted from Bio-oil. Chinese Journal of Chemical Engineering 18(6): $1018 \sim 1022$.

Jung, J.Y., Lee, Y., Lee, E.Y. 2016. Value-added Utilization of Lignin Residue from Pretreatment Process of Lignocellulosic Biomass. Applied Chemistry for Engineering 27(2): 135 144.

$\mathrm{Ku}$, C.S., Mun, S.P. 2006. Characterization of Pyrolysis Tar Derived from Lignocellulosic Biomass. J. Ind. Eng. Chem. 12(6): 853 861.

Kwon, G.J., Kwon, S.M., Cha, D.S., Kim, N.H. 2010. Characteristics of Pellet Prepared from Sawdust and Wood-tar. Journal of the Korean Wood Science \& Technology 38(1): 36 42.

Kwon, G.J., Kwon, S.M., Jang, J.H., Chun, K.W., Kim, N.H. 2011. Weathering of Larch Wood treated with Wood tar and Wood vinegar. Journal of Forest and Environmental Science 27(1): $55 \sim 60$.
Lee, A., Deng, Y. 2015. Green polyurethane from lignin and soybean oil through non-isocyanate reactions. European Polymer Journal 63: 67 73 .

Liu, W.J., Jiang, H., Yu, H.Q., Elhalem, S.S.A., Shen, D., Xiao, R., Zhong, M., Hashmi, A., Xu, J., Motkuri, R.K., Fernandez, C.A., Liu, J., Tucker, M.P., McGrail, P.B., Yang, B., Nune, S.K. 2015. Thermochemical conversion of lignin to functional materials: a review and future directions. Green Chemistry 17: 4888 4907.

Lora, J.H., Glasser, W.G. 2002. Recent Industrial Applications of Lignin: A Sustainable Alternative to Nonrenewable Materials. Journal of Polymers and the Environment 10(1-2): 39 48.

Mohan, D., Pittman, C.U., Steele, P.H. 2006. Pyrolysis of wood/biomass for bio-oil: A critical review. Energy and Fuels 20(3): 848 889 .

Mullen, C.A., Strahan, G.D., Boateng, A.A. 2009. Characterization of various fast-pyrolysis bio-oils by NMR spectroscopy. Energy \& Fuels 23(5): $2707 \sim 2718$.

Mun, S., Ku, C., Park, S. 2007. Physicochemical Characterization of Pyrolyzates Produced from Carbonization of Lignocellulosic Biomass in a Batch-type Mechanical Kiln. Journal of Industrial and Engineering Chemistry 13(1): 127 $\sim 132$.

Mun, S.P., Ku, C.S. 2010. Pyrolysis GC-MS analysis of tars formed during the aging of wood and bamboo crude vinegars. Journal of Wood Science 56(1): 47 52.

Park, Y., Doherty, W.O.S., Halley, P.J. 2008. Developing lignin-based resin coatings and composites. Industrial Crops and Products 27(2): $163 \sim 167$.

Prauchner, M.J., Nya, V., Pasa, M.D., Otani, C., Otani, S. 2001. Characterization and Thermal Polymerization of Eucalyptus Tar Pitches. Energy \& Fuels 15(2): 449 454. 
Rocha, J.D., Coutinho, A.R., Luengo, C.A. 2002. Biopitch produced from eucalyptus wood pyrolysis liquids as a renewable binder for carbon electrode manufacture. Brazilian Journal of Chemical Engineering 19(2): 127 132.

Saiz-Jimenez, C., De Leeuw, J.W. 1986. Lignin pyrolysis products: Their structures and their significance as biomarkers. Organic Geochemistry 10(4-6): 869 876.

Sarohia, G.S., Ghuman, H.S., James, A.K., Thring, R.W., Plourde, G.L. 2014. Characterization of Tar From Wood Pellet Production. International Journal of Chemistry 6(4): 1 11.

Scholze, B., Hanser, C., Meier, D. 2001. Characterization of the water-insoluble fraction from fast pyrolysis liquids (pyrolytic lignin). Journal of Analytical and Applied Pyrolysis 58-59(1): 387 400.
Setua, D.K., Shukla, M.K., Nigam, V., Singh, H., Mathur, G.N. 2000. Lignin reinforced rubber composites. Polymer Composite 21(6): 988 995.

Steiner, C., Teixeira, W.G., Zech, W. 2004. Slash and Char: An Alternative to Slash and Burn Practiced in the Amazon Basin, in: Glaser, B., Woods, W.I. (Eds.). Springer Berlin Heidelberg, pp. $183 \sim 193$.

Wenzl, H.F.J. 1970. The chemical technology of wood. Academic Press.

Yatagai, M., Unrinin, G., Sugiura, G. 1986. By-products of wood carbonization. Tars from mangrove, sugi ogalite, wheat straw, and Chishima-sasa. Mokuzai Gakkaishi. 32(6): 467 471.

Zhao, B., Chen, G., Liu, Y., Hu, K., Wu, R. 2001. Synthesis of lignin base epoxy resin and its characterization. Journal of Materials Science Letters 20: $859 \sim 862$. 